\title{
Editorial
}

\section{Editorial: Interdisciplinarity and Instructional Design in Technology}

\author{
Betül C. Czerkawski \\ Editor, ITET
}

\author{
Nicole Schmidt \\ Managing Editor, ITET
}

\begin{abstract}
Higher education today is still constructed through discipline-based approaches. To build a true interdisciplinary curriculum, instructional designers must begin with student needs and expected learning outcomes, which are not discipline specific. It is our hope that, in the near future, instructional design and technology programs will become more visible in the university settings as fine examples of interdisciplinary teaching and research..
\end{abstract}

Keywords: interdisciplinarity; instructional design; higher education; technology

Higher education today is still constructed through discipline-based approaches. The industrialization of the 18th century provided a basis for mass education of the workforce, and clear disciplinary fields provided a solid and reliable backdrop for such education at that time. However, two decades into the 21st century, this disciplinary system no longer responds to the needs of the society at large. Today, we tackle complex problems, confront new technologies that mimic human behaviors, such as A.I., and operate within a highly diversified economic structure. Yet one wonders why disciplinary boundaries in higher education have remained largely unchanged. The disciplines represented in today's higher education system are isolated and detached from real life experiences, and their abstract constructions do not solve the problems we currently face.

Interdisciplinarity in higher education requires thorough planning and deep thinking, resulting in drastic changes across institutions. New organizational and administrative structures are created, new criteria for academic rigor is developed, and new pedagogical approaches are formed to establish interdisciplinarity as the foundation of higher education. Due to the enormity and complexity of the issue, most universities today offer interdisciplinary programs in some form and substantially support such new initiatives, though core structures are preserved within disciplinary boundaries. In other words, while there is a desire to include interdisciplinarity, it is a slow-moving process.

Instructional design and technology is an interdisciplinary field. We borrow from educational and cognitive psychology to explain the learning process and from sociology 
to understand the classroom environment. We draw on economics to calculate costand-effect of educational services and from information science to study affordances of technologies. To build a true interdisciplinary curriculum, instructional designers must begin with student needs and expected learning outcomes, which are not discipline specific. Depending on the nature of these outcomes, instructional designers collaborate with experts from various disciplines to find the best solutions and foster specific learning outcomes. Interdisciplinarity does not mean denying current disciplinary structures, but it instead requires a fine-tuned integration of those disciplines into real life experiences and situations. Instructional designers create learning environments to conceptualize problems at hand, rather than conforming to strict disciplinary boundaries.

In this issue of ITET, and in all others, you will see manuscripts from various disciplines where the authors describe a process, procedure, or model, in search of a well-designed learning experience that addresses real life issues and problems. It is our hope that, in the near future, instructional design and technology programs will become more visible in the university settings as fine examples of interdisciplinary teaching and research. These programs play an important role in connecting and relating various academic disciplines by providing the synthesis of disciplinary knowledge to meet students' needs while solving authentic problems. 